Abstract ID: 42

\title{
Conus Medullary Syndrome secondary to Spinal Schwannoma : A report of 3 cases
}

Ed Simor Khan Mor Japar Khan ${ }^{\mathrm{a}}$ | Nur Akmal Ismail Ismail Mansor ${ }^{\mathrm{a}}$ | Mohd Ariff Sharifudin ${ }^{\mathrm{a}}$ | Mohd Adham Shah Ayeop $^{\mathrm{a}}$ | Chan Kin Hup ${ }^{\mathrm{b}}$ | Mohamed Saufi Awang ${ }^{\mathrm{b}}$ | Zamzuri Zakaria ${ }^{\mathrm{a}}$

${ }^{a}$ Department of Orthopaedics, Traumatology \& Rehabilitation, Kulliyyah of Medicine, International Islamic University Malaysia

${ }^{b}$ Department of Surgery, Kulliyyah of Medicine, International Islamic University Malaysia

Spinal Schwannoma originates from the Schwann cells, hence it is called Schwannoma. The tumor localization is in various parts of the spinal cord, but prevails in cervical and thoracic. In the literature 70 to $80 \%$ of spinal schwannomas are reported to be intradural in location, and $15 \%$ with both intradural and extradural components. All 3 cases were female in their 4th-5th decade, presented with either low back pain, radiculopathy, weakness of both lower limbs associated with urinary incontinence. MRI revealed a well defined mass adjacent to conus medullary area located intradural, extramedullary. All three patients underwent microscopic assisted excision of the tumour. All patients had Good Early Outcome. Spinal schwannoma causing Conus Medullary Syndrome is rare. Back pain and radicular pain were most common early presenting symptoms while urinary symptoms occur later. Schwannomas typically arise from a single nerve root originating from the schwann cells. To obtain total resection, the affected nerve root is commonly sacrificed in order to prevent recurrence. Intradural Extramedullary Schwannoma, even presented at a later stage with significant neurological deficit, has a Good Outcome post operatively owing to its Benign nature, Extramedullary location, and a Meticulous Microscopic assisted Complete Surgical Excision.

KEYWORDS: spinal schwannoma, cord compression 